\title{
WIP: Exploring Pedagogical Alternatives for Incorporating Simulations in an Introductory Power Electronics Course
}

\section{Mr. Mohamed Khaled Elshazly, University of Toronto}

Mohamed Elshazly is a Ph.D. candidate at the University of Toronto Edward S. Rogers Sr. Department of Electrical and Computer Engineering (ECE). He is currently engaged in developing support simulations for teaching introductory power electronics to undergraduate ECE students, as well as providing technical support. Mohamed's main research interests are numerical simulations and computational materials science, focusing on quantum mechanical modelling of electrochemical energy storage devices.

\section{Dr. Hamid S Timorabadi P.Eng., University of Toronto}

Hamid Timorabadi received his B.Sc, M.A.Sc, and Ph.D. degrees in Electrical Engineering from the University of Toronto. He has worked as a project, design, and test engineer as well as a consultant to industry. His research interests include the application of digital signal processing in power systems. 


\title{
WIP: Exploring Pedagogical Alternatives for Incorporating Simulations in an Introductory Power Electronics Course
}

\begin{abstract}
In Fall 2018, we developed LabSim, a set of circuit simulators for a power electronics fundamentals course based on a combination of Simulink and PLECS visual blocks. LabSim was developed to provide third-year electrical engineering students with an avenue for independent exploration beyond theory-heavy lectures and strictly controlled labs. The pedagogical approach then was to offer LabSim as a completely voluntary ancillary tool, with no involvement in lab or tutorial assignments, in order to minimize additional workload. While a student survey showed that LabSim accomplished its main goal of bridging the gap between lectures and labs, a common theme in the provided feedback was that students would benefit more from LabSim if it were incorporated more directly into their assignments. In response, we have updated the pedagogical approach in the Fall 2019 offering of the course to involve developing simulationcentred questions in pre-lab preparation assignments, dedicating office hours for simulationrelated questions, developing additional simulators for crucial converter circuits, and providing dedicated simulation workstations on campus. We present this updated pedagogical approach in detail along with an overview of technical updates and examples from the aforementioned assignments. We also present an evaluation of this new approach through an end-of-semester student survey coupled with LabSim usage data collection in assignments where it is optional.
\end{abstract}

\section{Motivation \& Introduction to Fundamentals of Electrical Energy Systems (FEES)}

Electrical engineering students specializing in energy systems are introduced to power electronics in their third year at our university. The introductory course, entitled Fundamentals of Electrical Energy Systems (FEES), covers DC/DC converters, DC/AC converters, three-phase circuits, as well as the basics of transformers and electrical machines. The bulk of the course material, however, is dedicated to switch-mode power conversion. The majority of lectures and tutorials are dedicated to explaining relevant concepts such as switch realization, pulse-width modulation (PWM), harmonics/power quality, and continuous/discontinuous conduction modes. Four out of a total of six laboratory sessions are centred around power electronic circuits.

Prior to Fall 2018, student feedback consistently revealed some shortcomings with the pedagogical structure of FEES. The course was rigidly divided into a theoretical portion (lectures + tutorials) and a practical portion (laboratory sessions). The lectures are math heavy and packed with information, while laboratory sessions are strictly controlled due to the safety concerns associated with high-power circuits. Students are expected to follow and understand the theoretical operation of switch-mode circuits in lectures and tutorials, which requires proficiency in many areas of fundamental science and electrical engineering such as circuit theory, electronic devices, signal processing, and complex analysis. The lab sessions, while highly beneficial in 
terms of providing experience with practical circuits, utilize converters that are operated in a black box manner by the students. This causes some difficulty in relating theoretical concepts to practical circuit operation, particularly with switching control where students are unaware of the algorithms being used. Moreover, the strict safety measures and lengthy instruction-based experimental procedures leave little room for independent exploration or trial and error.

In Fall 2018, motivated by the many promising reports of incorporating simulations in undergraduate classrooms [1 - 6], we developed LabSim. LabSim is a set of simulation files for various switch-mode power converters implemented in Simulink [7] using visual PLECS blocks [8]. The purpose of LabSim is to provide students with an avenue for independent conceptual exploration beyond quantitative/analytical proofs and experimentation beyond the rigid instruction-based laboratory sessions. The decision to use Simulink/PLECS was motivated by three reasons: (1) Simulink and PLECS are regarded as an industry-standard combination for power electronics engineers, (2) this software combination is already used extensively in advanced undergraduate and graduate power electronics courses at our university, and (3) PLECS provides important performance advantages and numerical stability by modelling circuit components as piecewise linear functions [9], which enables students to run fully fledged switched-mode models on their personal computers and not be limited by the shortcomings of state-space-averaged models. A more detailed discussion of the technical challenges associated with simulating power electronics circuits and how LabSim addresses them can be found in our inaugural LabSim study [10].

The pedagogical approach in 2018 was to offer LabSim as a completely voluntary ancillary tool, with no involvement in lab or tutorial assignments. This hands-off approach was developed to ensure only a minimal addition to the workload and performance pressure of an already dense course. LabSim-related teaching activities were limited to a general demonstration in the second week of the semester and written manuals posted with each of the simulation files. While a student survey showed that LabSim did indeed accomplish its main goal of bridging the gap between lectures and labs, a common theme in the provided feedback was that students would benefit more from LabSim if it is incorporated more directly in their assignments. Many students emphasized that if LabSim was present in their course material to a more significant degree, they would be more motivated to invest time into learning and using it.

While utilizing simulations in undergraduate courses has been explored extensively in the past decade, there is no consensus on a universally successful strategy for incorporating them into a given curriculum. Akkoyun developed a simulation tool to model the processing system of a natural stone plant, incorporating it into lectures for mining engineering as well as vocational high school students [6]. Akkoyun mainly used simulations in-lecture to convey technical information and explore process optimization scenarios suggested by students in class discussions (e.g. to decrease material waste and increase recovery). Rios and Fadda incorporated 
SolidWorks 3D simulations into a first-year course for mechanical engineering design, covering concepts such as kinematic motion, structural integrity, fluid flow and heat transfer [11]. In this case, the simulations were directly incorporated into the design lab material while providing an instructor and graduate teaching assistants to oversee the process and instruct students on SolidWorks usage during lab sessions. Danesh-Yazdi and coworkers designed a set of graphical simulations in MATLAB to assist with teaching a course on vibrations, opting to incorporate the simulations both as a lecture demonstration tool and in dedicated computer-based assignments [12]. Abramovitz used state-space-averaged PSPICE models of power electronic converters and active power factor correction (APFC) circuits as pre-lab assignments for an industrial electronics laboratory course [13].

All the aforementioned examples reported positive educational outcomes through instructor evaluation, student surveys, or a combination of the two, suggesting that the pedagogical strategy of incorporating simulations at the undergraduate level can be developed on a case-by-case basis. This ensures the pedagogy is suitable for the specific scientific topics, technical challenges, and sought educational outcomes of the course. Therefore, we have devised an alternative pedagogical approach for incorporating LabSim into the Fall 2019 offering of the course, which is the focus of this study. The updated approach involves developing simulation-centred questions in pre-lab preparation assignments, dedicated office hours for technical troubleshooting/simulation-related discussions, developing additional simulation files for crucial converter circuits, and providing dedicated simulation workstations on campus. We have also made an effort to preserve the most successful elements of the previous approach such as using industry-standard software, providing students with licenses to install software on their personal computers, and designing assignments in a manner that makes the use of LabSim largely optional. We present this updated pedagogical approach in detail with examples from the aforementioned assignments.

To evaluate the new approach, an end-of-semester student opinion survey is conducted anonymously on the course's Canvas page. The survey focuses on 3 key areas: educational outcome, workload, and technical (software) issues. The survey results are compared with those from the 2018 offering of the course. Additionally, we gauge interest in LabSim by collecting data about the number of students who opt to use it in assignments where they are given a choice between a simulation-based solution or a traditional analytical approach.

\section{Overview of LabSim Circuits and Technical Updates}

The general layout of all LabSim circuits, as introduced in [10], is shown in Figure 1. Every LabSim file consists of Control Inputs, Converter Circuit, and Instrumentation. Control Inputs cover the value of the DC input voltage and the switching control signal sent to the transistors. Control inputs are always built using Simulink blocks. The Converter Circuit is a PLECS circuit 
model containing power components: DC power supply, AC grid supply, transistors, filter components, voltage/current sensors, and load. Instrumentation blocks simulate the measuring equipment students use in the lab: oscilloscopes, metres, and harmonic analyzers. Like Control Inputs, Instrumentation is implemented using standard Simulink blocks.

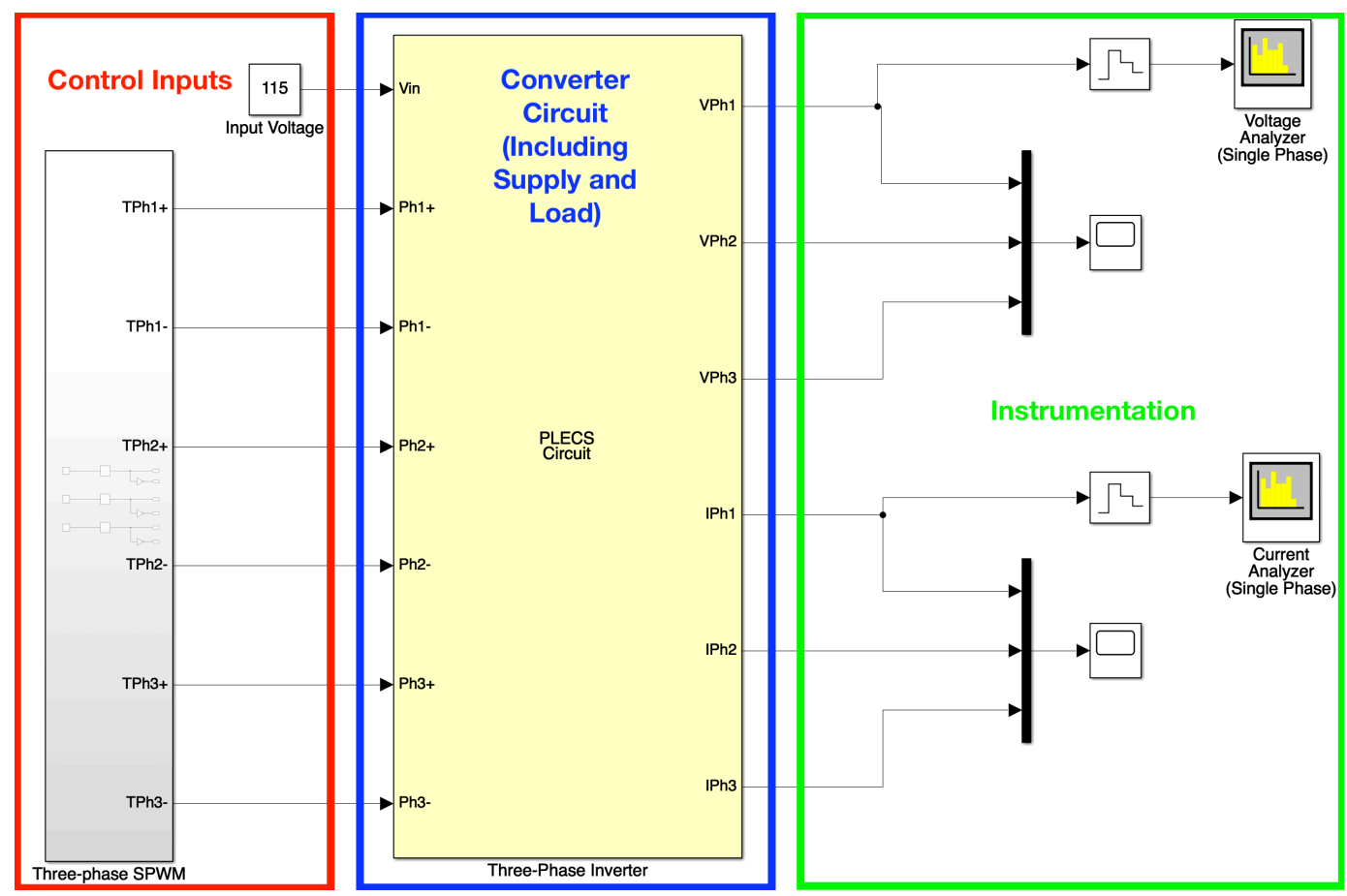

Figure 1 - Main components of LabSim models demonstrated on a three-phase inverter circuit simulator.

The specific electrical elements and sub-blocks of each LabSim component depend on the circuit being simulated. In the Fall 2018 pilot project, we provided students with five basic converter circuits: DC/DC converters (buck, boost, buck-boost), a single-phase full bridge PWM inverter, and a three-phase PWM inverter. All the circuits operated in isolation from the grid with simple resistive loads. A brief illustration of a sample converter circuit (buck) and its capabilities can be found in Appendix A. A more detailed explanation of these simple converters can be found in [10].

In the Fall 2019 offering, LabSim was updated with the addition of two circuits: a grid-connected single-phase inverter and a delay-angle-controlled H-bridge voltage source inverter (VSI). These advanced circuits have long been part of the FEES curriculum, in lectures and labs, and are consistently cited by students as two of the most challenging circuits to understand. Therefore, developing their LabSim counterparts was the top priority for the 2019 technical update. Figure 2 shows the circuit model and control inputs for the H-bridge VSI with delay angle control. 

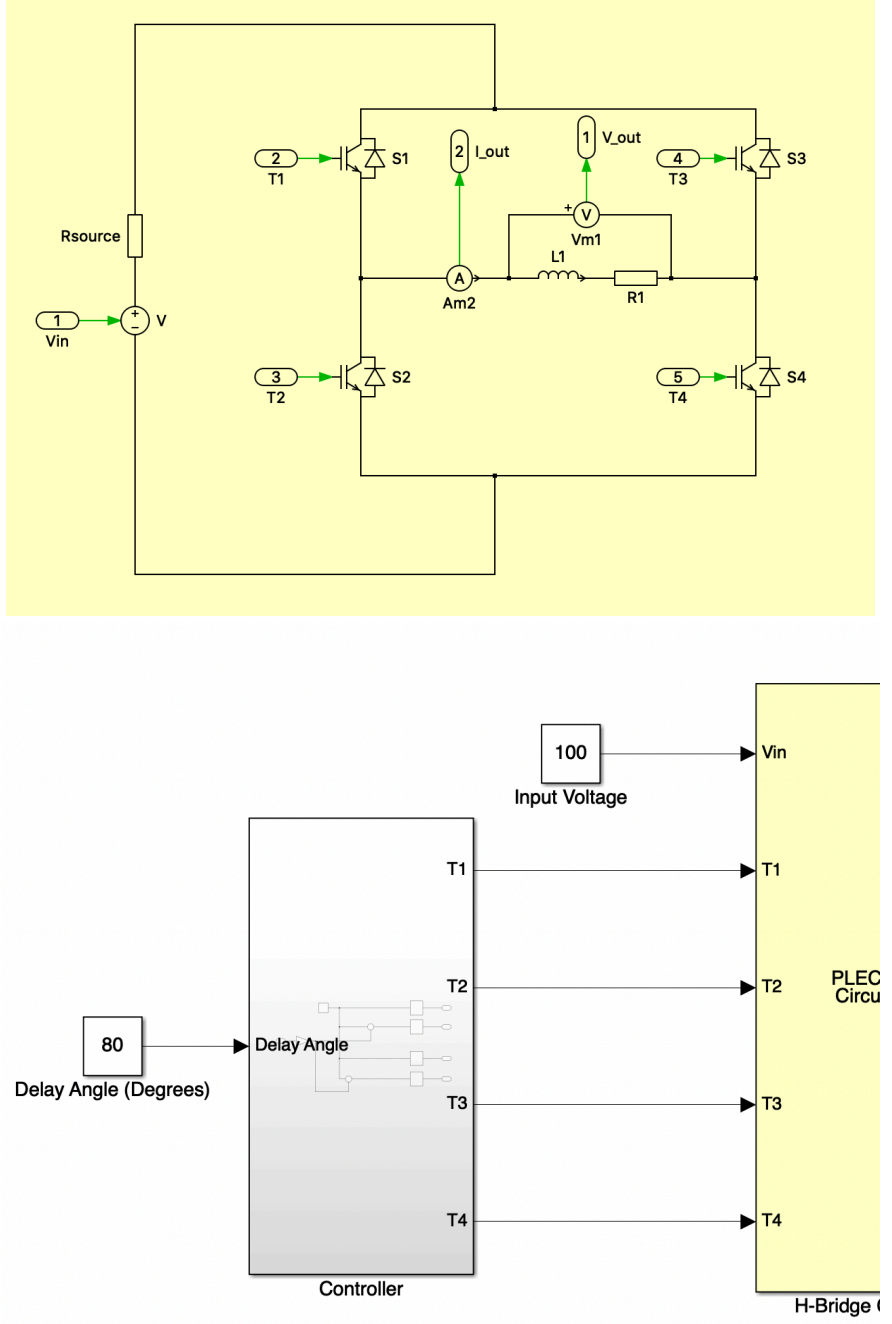

Figure 2 - Top: PLECS circuit and Bottom: Control Inputs for the H-bridge VSI with delay angle control.

The main purpose of the H-bridge VSI LabSim circuit is to illustrate the influence of the delay angle $(\delta)$, introduced during polarity transition, on the output voltage and current waveforms of a square wave inverter. The delay angle can take any value between $0^{\circ}$ and $180^{\circ}$, which correspond to no delay or a full half-cycle delay, respectively. Switching frequency can be changed in the Controller block. The expected voltage waveform for a general value of $\delta$ is a quasi-square wave like the one shown Figure 3. Since the current waveform will depend on the voltage as well as other circuit parameters, students are encouraged to experiment with values of $\delta$, switching frequency, and RL load impedance to understand how the interplay between the different parts of the circuit influences the output, as illustrated in Figure 3. 

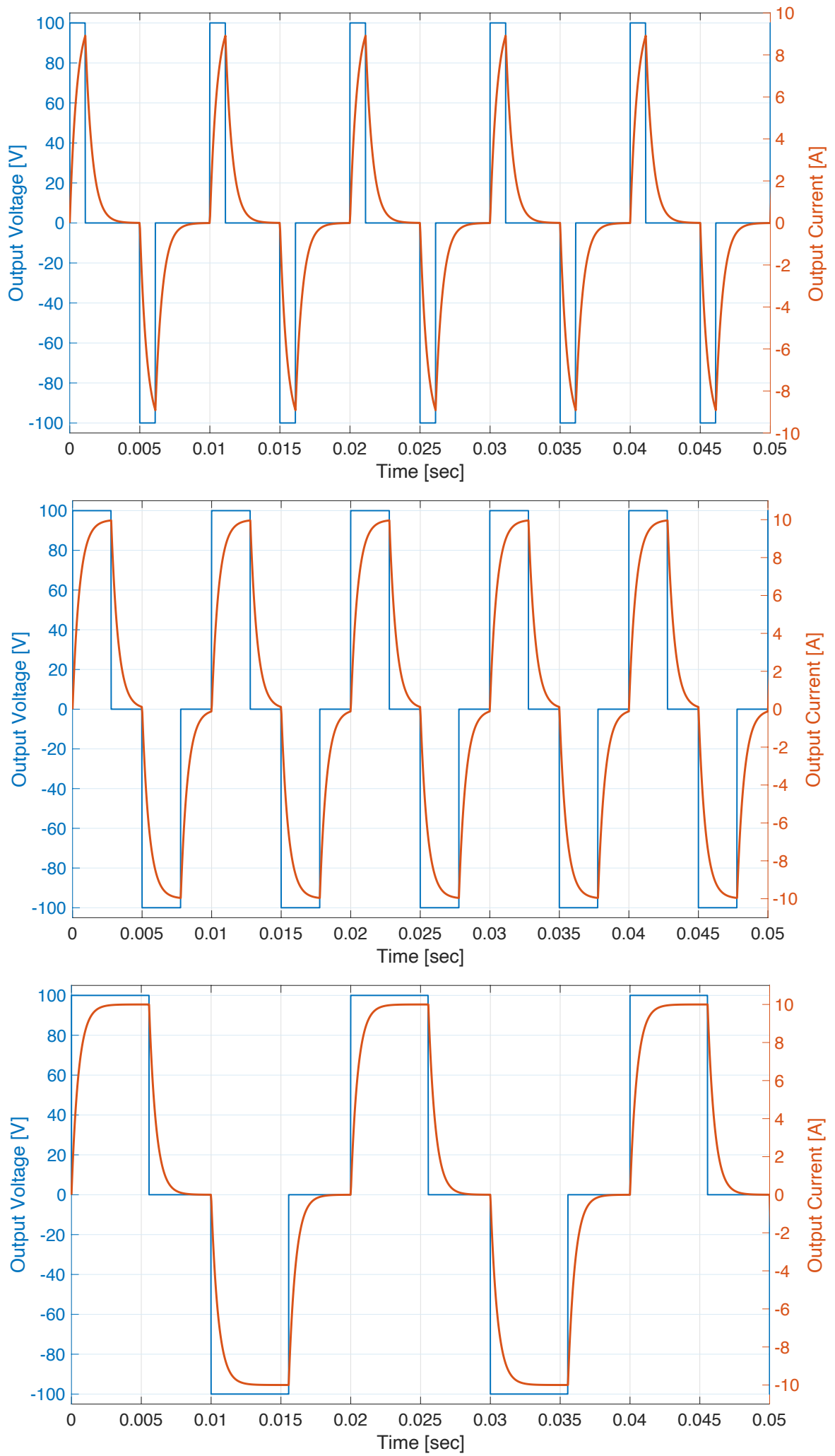

Figure 3 - Output voltage and current waveforms the H-bridge VSI with delay angle control.

Top: Switching Frequency $=100 \mathrm{~Hz}$ and $\delta=140^{\circ}$

Middle: Switching Frequency $=100 \mathrm{~Hz}$ and $\delta=80^{\circ}$

Bottom: Switching Frequency $=50 \mathrm{~Hz}$ and $\delta=80^{\circ}$ 
A more advanced update to LabSim is the addition of the grid-connected inverter circuit, shown in Figure 4. This simulation is designed to mimic a similar lab experiment in FEES to a very accurate degree. The inverter circuit is fed by a DC source and is connected to an AC grid at the converter output. The focus of this simulation is not the inverter circuit itself, which is explained in a simpler simulation of an isolated inverter, but the demonstration of the principles behind bidirectional power flow between the DC source and the AC grid. This includes control over both active and reactive power flow as well as power factor correction.

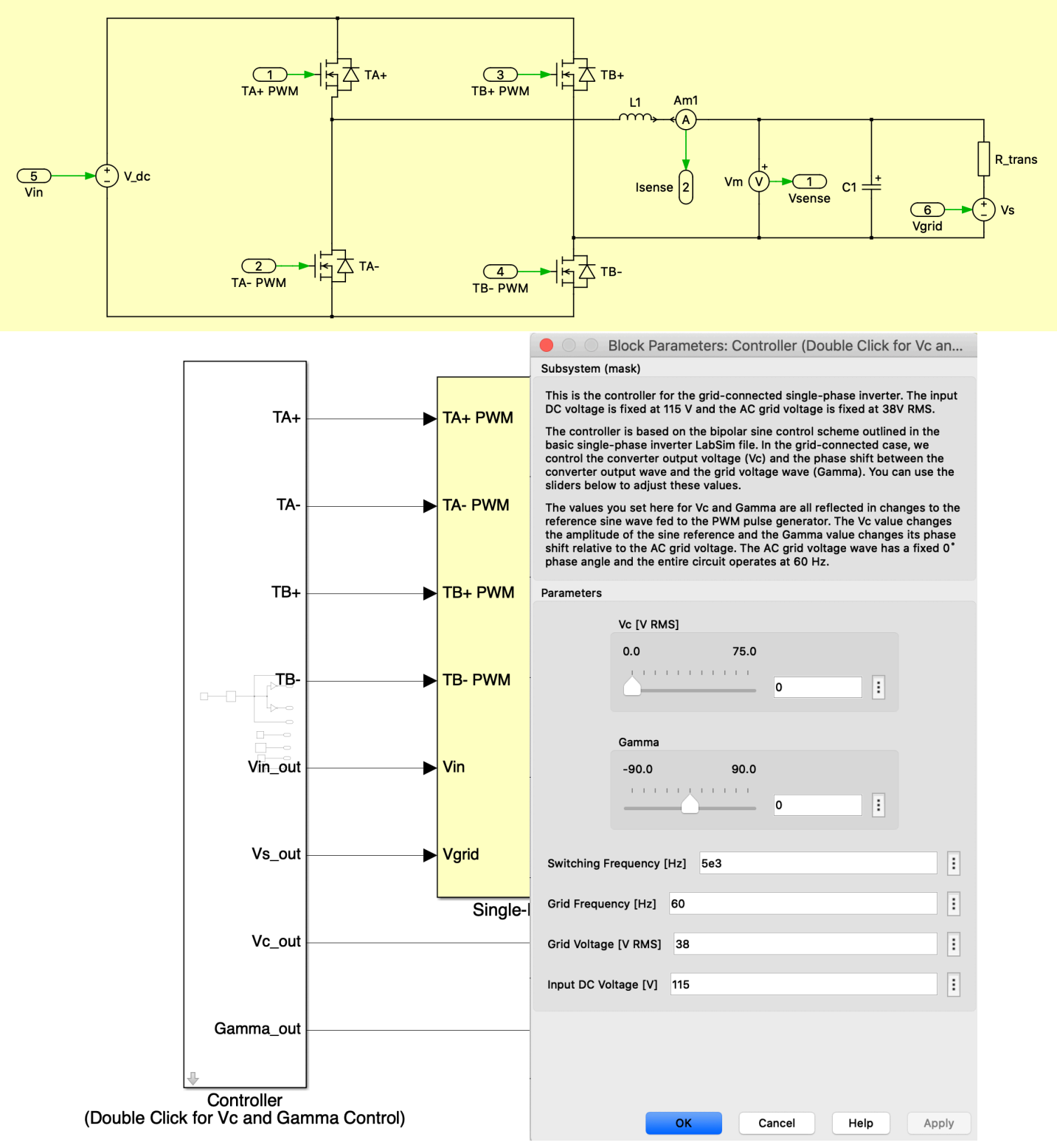

Figure 4 - Grid-connected single-phase PWM inverter

Top: PLECS Circuit Model

Bottom Left: Control Inputs

Bottom Right: Controller Dialog Box 
As shown in Figure 4, the control inputs are all lumped under the "Controller" block. If the block is double-clicked, a dialog box appears with 6 controllable parameters:

1. Vc: The converter's RMS output voltage.

2. Gamma: The phase shift between the Vc wave and the wave of the AC grid.

3. Switching frequency: The carrier frequency of the PWM generator.

4. Grid Frequency: The frequency of the grid voltage and the Vc output voltage waves.

5. Grid Voltage: The RMS voltage provided by the utility/transformer.

6. Input DC Voltage: The input DC voltage to the inverter.

Underneath the mask, the control input it is based on a bipolar sine PWM switching scheme. Adjusting the Vc slider changes the amplitude of the reference wave to a calibrated value between 0 and 1, while adjusting the Gamma slider changes its phase angle. Students can explore the various combinations of $\mathrm{Vc}$ and Gamma to understand their influence on the magnitude and direction of power flow between the DC source and the AC grid.

The instrumentation for grid-connected inverter is shown in Figure 5. It consists of a measurement module connected to 5 displays: apparent power $(\mathrm{S})$, active power $(\mathrm{P})$, reactive power (Q), RMS voltage magnitude (|Vs $\mid)$, and RMS current magnitude $(|\mathrm{Is}|)$. The sign of the active power display indicates whether that power is flowing from the DC source to the AC grid (negative) or from the grid into the converter/DC source (positive). The polarity is a convention that is chosen to match that of the laboratory experiment. Students can also use the provided scope to visually inspect the influence of switching frequency and filter sizes on current ripple, as well as the influence of Vc and Gamma on the current waveform, as shown in Figure 5.
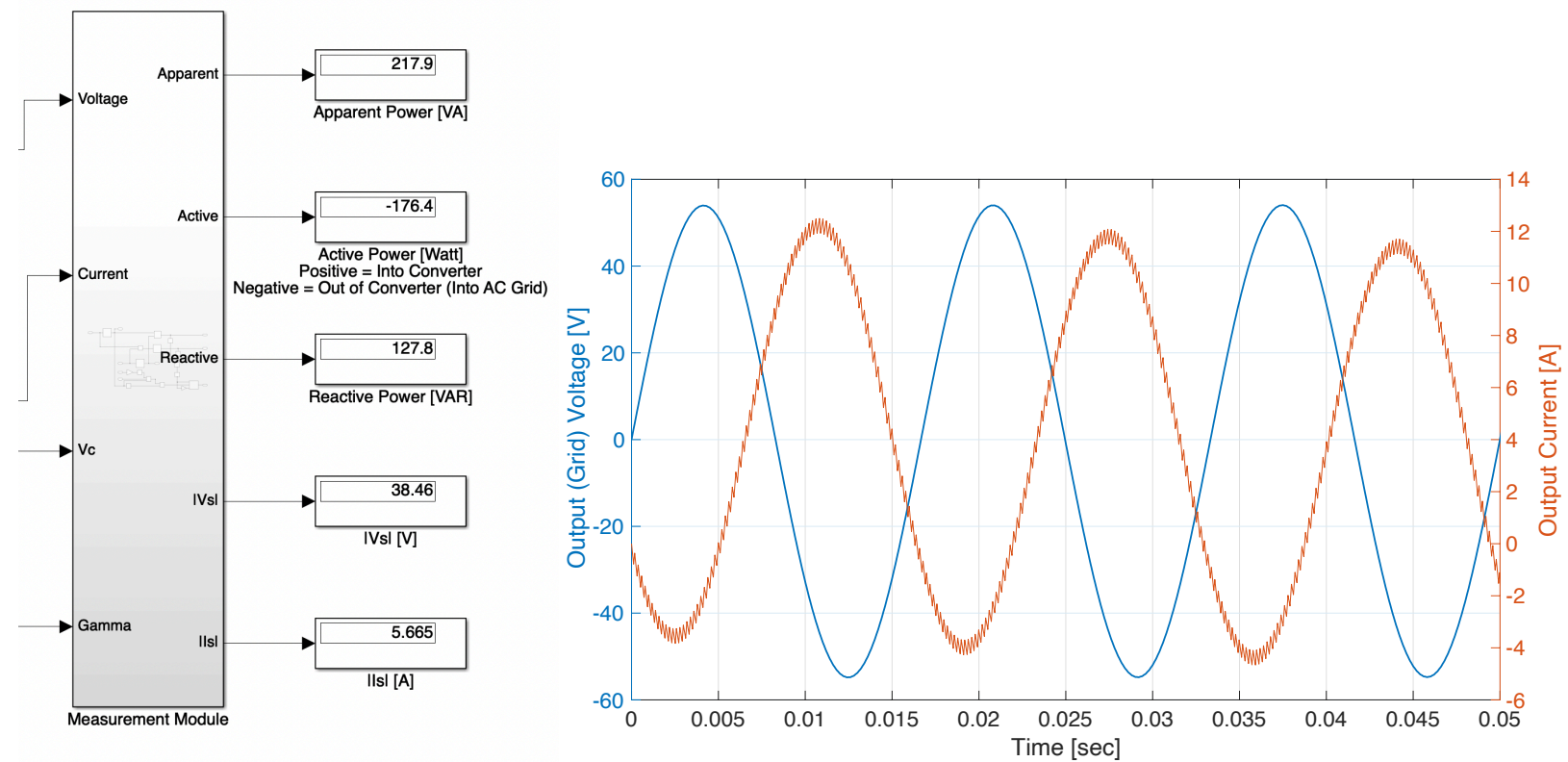

Figure 5 - Power flow instrumentation (left) and output current waveform (right) for the grid-connected inverter at $\mathrm{Vc}=34.5 \mathrm{~V}$, Gamma $=61.2^{\circ}, \mathrm{Vs}=38 \mathrm{~V}$, and a switching frequency of $5 \mathrm{kHz}$. 


\section{Pedagogical Strategy}

FEES students have access to both MATLAB and PLECS free of charge at our university. Students were provided with PLECS codes and instructions for installation at the beginning of term so they are able to run LabSim on their personal computers. This was first done in the Fall 2018 pilot project and was maintained for the Fall 2019 offering due to positive feedback from past students regarding the convenience of running LabSim at home. Students are also provided with step-by-step manuals to guide them through the installation and licensing processes for both MATLAB and PLECS.

During the first laboratory session, which takes place two weeks into term, students are given a demonstration on the basics of LabSim and working with Simulink in general. A portion of the lab session is also dedicated to troubleshooting and technical support with issues related to installation and licensing on students' personal computers. Simulation files were then provided to students in pace with the relevant lab experiments, each file accompanied by a detailed user guide explaining how the model can be used and modified. Students were also provided with a dedicated TA for LabSim support through email and office hours.

In the Fall 2018 pilot project, the demo session was the full extent of LabSim's direct involvement in the FEES course material or teaching activities. Using the simulations was completely voluntary in order to avoid imposing additional workload on the students. LabSim was not incorporated in lectures, tutorials, or labs. While an evaluation survey showed most students had a favourable opinion of LabSim, students consistently said they would have benefited more had it been incorporated into the pre-lab preparation assignments. Some students also mentioned they were not motivated to use it, despite encouragement from the instructor and TAs, since it had no direct impact on their performance in assignments. Some students also reported difficulties installing and running the software on their personal and/or general-purpose university computers, leaving them at a disadvantage.

In the Fall 2019 offering, we addressed those shortcomings with a four-pronged approach:

1. Directly incorporate LabSim into pre-lab preparation assignments as simulation-centric problems.

2. Develop simulations for challenging, more advanced circuits that mimic the circuits students operate in the lab.

3. Collect data on LabSim usage in assignments where simulation problems are optional to gauge student interest.

4. Coordinate with the energy systems lab to provide and maintain dedicated workstations for running LabSim on a first come, first served basis. 
There are four laboratory sessions focused on power electronics throughout the semester involving pre-lab assignments. In the first pre-lab assignment, LabSim was incorporated as mandatory simulation-based problems. This was done to ensure students get exposed to LabSim early on in the semester while the circuits are simple and the workload is light. This has the added benefit of detecting and addressing technical issues in the early stages of the semester with the help of the TA. Afterwards, each pre-lab assignment included one or two problems that can be answered either analytically or using LabSim. Samples of LabSim-related questions from the various pre-lab assignments can be found in Appendix B.

\section{Evaluation \& Student Reception}

An anonymous online survey was conducted between the $10^{\text {th }}$ and $13^{\text {th }}$ weeks of the semester on the course's online Canvas portal [14]. 40 out of the 43 registered students completed the survey, corresponding to a participation rate of $93 \%$. The Fall 2019 survey was identical to that of the Fall 2018 pilot project in order to facilitate direct comparison between the two pedagogical strategies.

The survey consisted of 23 five-point Likert items grouped into three scales:

1. Educational Outcome. This measures students' perception of how relevant LabSim is to the course material and the impact it had, if any, on improving their understanding of the circuits they operated in the lab.

2. Workload. This measures students' perception of LabSim's impact on the overall course workload and whether there is perceived worth in any additional workload.

3. Technical. This assesses the ease of installation, use, and modification of LabSim models and related software on personal and university computers.

Students were also provided with three open-ended text fields where they can provide comments and suggestions related to each of the aforementioned metrics.

Each survey item is a statement to which students can provide one of five responses, ranging from "strongly disagree" to "strongly agree". All survey items were phrased consistently such that agreement would correspond to a positive opinion and disagreement would correspond to a negative opinion of the item being assessed. Figure 6 summarizes the responses of survey participants for each of the three performance metrics. As Table 1 shows, a Cronbach's Alpha range of $0.69-0.85$ shows acceptable to good internal consistency for every question group [15] [16]. The detailed questionnaire and student responses are provided in Appendix C. 
Table 1 - Values of Cronbach's Alpha for each question group in the survey.

\begin{tabular}{|c|c|c|}
\hline Metric & $\begin{array}{c}\text { Number } \\
\text { of Items }\end{array}$ & $\begin{array}{c}\text { Cronbach's } \\
\text { Alpha }\end{array}$ \\
\hline $\begin{array}{c}\text { Educational } \\
\text { Outcome }\end{array}$ & 7 & 0.85 \\
\hline Workload & 7 & 0.78 \\
\hline Technical & 9 & 0.69 \\
\hline
\end{tabular}

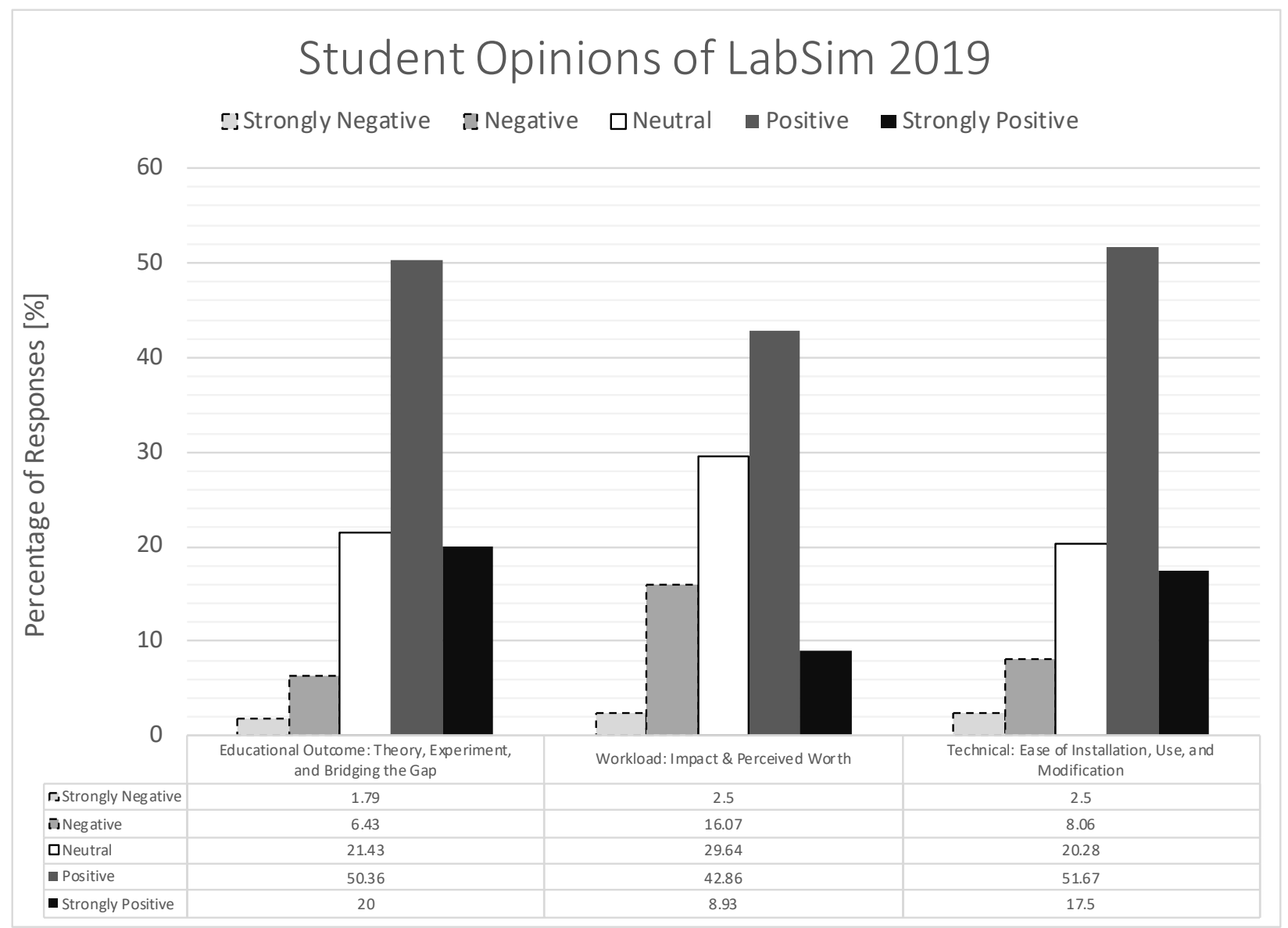

Figure 6 - Student opinions of LabSim for the three performance metrics.

Students' responses were highly positive in the educational outcome group of questions. $87 \%$ agreed or strongly agreed that LabSim was relevant to the lecture material and $82 \%$ agreed or strongly agreed it was relevant to the laboratory experiments. $62 \%$ agreed that LabSim helped them understand the lecture material better and $72 \%$ agreed or strongly agreed it helped them understand lab experiments better. Crucially, 70\% agreed or strongly agreed that LabSim helped them connect the theory they learn in class to the laboratory experiments. 
Student attitudes towards workload issues were also positive. $65 \%$ agreed they had time to use LabSim and $60 \%$ agreed or strongly agreed it was not a significant addition to their workload. $77 \%$ of students reported that LabSim helped them reduce the workload associated with understanding lab experiments, but the majority did not report a similar impact on understanding lecture material. Interestingly, 70\% agreed or strongly agreed that the additional workload is justified by the skills they gained using Simulink and PLECS. A similarly positive reaction was found for the Fall 2018 pilot project, which once again highlights the importance of using industry-standard simulation software since students perceive it as a form of professional development.

Students' attitudes towards the technical aspects of LabSim were also highly positive, with $82 \%$ agreeing or strongly agreeing they were able to run it on their personal computers without problems and $80 \%$ agreeing or strongly agreeing that the circuit models were easy to relate to the lab experiments and schematics they use in class. $77 \%$ agreed or strongly agreed that the Simulink instrumentation helped them understand the operation of the circuit and $75 \%$ agreed or strongly agreed that the control inputs were easy to understand. 77\% agreed or strongly agreed that it was easy to modify the provided circuit models.

Figure 7 shows a comparison between the survey results from the Fall 2018 pilot project and those from the Fall 2019 offering. It is clear that the updated pedagogical strategy has resulted in significant improvement in student opinions across the three assessment categories. Two improvements in particular are noteworthy:

1. For Educational Outcome and Technical Issues, the percentage of negative or strongly negative opinions did not change significantly. The majority of positive gains seem to have been generated out of what would have been otherwise neutral responses, which suggests that more students were encouraged to use LabSim upon changing the pedagogical strategy from completely hands-off to direct incorporation into course material.

2. Despite LabSim usage being mandatory in one pre-lab assignment and incorporated in every subsequent assignment, a majority of students reported a positive opinion on workload-related issues.

Student feedback provides further insight into these improvements. Some students explicitly mentioned that giving students a choice in using LabSim for most pre-labs ensured they didn't feel pressured to invest time into learning the circuits when it was scarce. Other students found value in the extra work they invested, either because it helped them gain an intuitive understanding of lab circuits or because they were motivated to gain experience with Simulink and PLECS. Surprisingly, the most recurrent theme in student feedback was that LabSim should have an even larger presence in their course material. Many students especially suggested it be used as a demonstration tool during lectures and as an ancillary tool for verifying solutions in tutorials. This is an attractive course of action for future offerings given the positive feedback. 


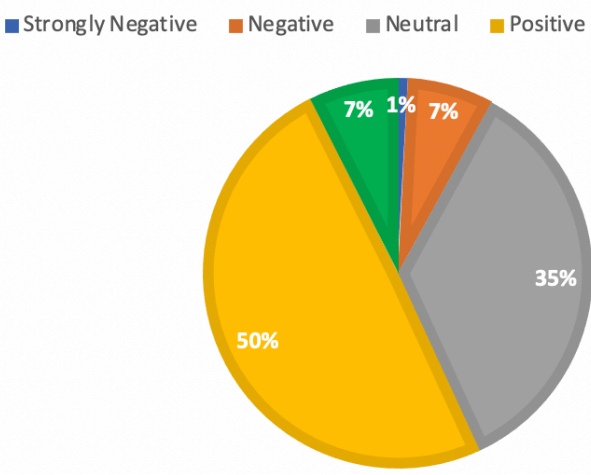

WORKLOAD 2018
-Strong ly Negative

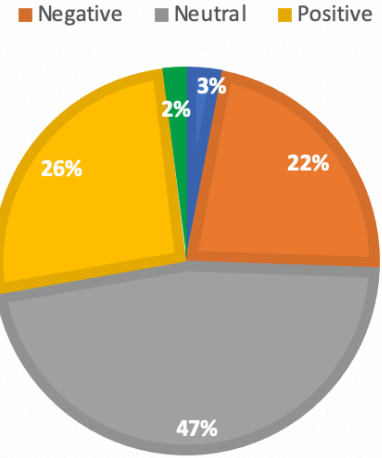

TECHNICAL 2018

- Strongly Negative

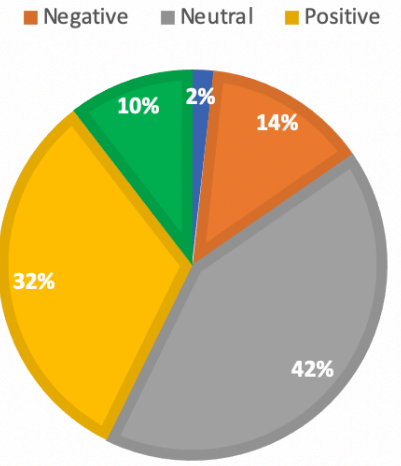

- Strongly Positive Strongly Negative

Negative Neutral $\quad$ Positive

- Strongly Positive

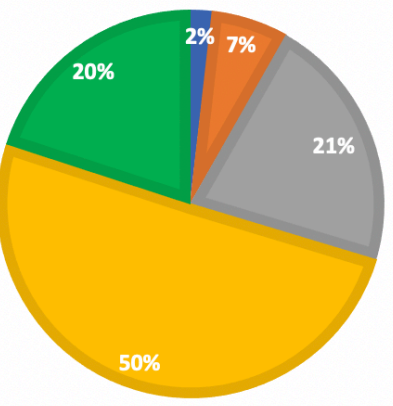

WORKLOAD 2019

- Strong ly Positive $\quad$ Strongly Negative

- Negative Neutral Positive Strongly Positive

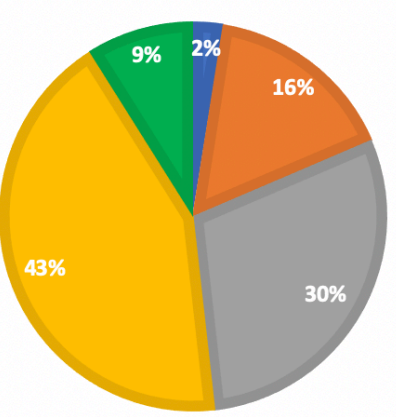

TECHNICAL 2019

- Strongly Positive $\quad$ Strongly Negative

negative Neutral $\square$ Positive $\square$ Strongly Positive

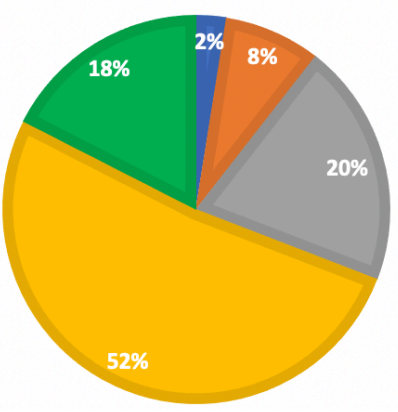

Figure 7 - Comparison between student opinions of LabSim in the Fall 2018 pilot project with the hands-off pedagogical approach and those of the Fall 2019 offering with the updated pedagogical strategy.

Another frequent suggestion in student feedback is to increase the number of mandatory LabSim questions in pre-lab assignments. Some students mentioned they were eager to learn and use LabSim circuits for their assignments, but simply found it quicker and/or more direct to answer the optional problems theoretically under the time constraints. This view is supported by the data collected by TAs from pre-lab assignments where LabSim usage was optional. The fraction of 
students who used LabSim for those assignments ranged between $7 \%$ and 55\%, presumably depending on the topic and the nature of the problem. Given that most students expressed openness to increasing LabSim presence in their course material, an even more effective strategy may be to develop assignments containing a combination of mandatory theoretical and simulation-based problems. In addition to providing students with a stronger incentive to learn simulation-based analysis, it would open an avenue for instructors and TAs to exploit the benefits of both analytical and simulation-based reasoning as complementary rather than competitive.

\section{Conclusions and Future Work}

LabSim, a set of power electronic circuit simulators based on a combination of Simulink and PLECS visual blocks, was developed in Fall 2018 to provide students of a power electronics fundamentals course with an avenue for independent exploration. The pedagogical approach then was to offer LabSim as a completely voluntary ancillary tool, with no involvement in lab or tutorial assignments, in order to minimize additional workload. While a student survey showed that LabSim accomplished its main goal of bridging the gap between lectures and labs, this approach provided little incentive for students to use the simulations and exploit their full potential. In response, we have updated the pedagogical approach in the Fall 2019 offering of the course to involve developing simulation-centred questions in pre-lab preparation assignments, dedicating office hours for simulation-related questions, developing additional simulators for crucial converter circuits, and providing dedicated simulation workstations on campus.

The new pedagogical strategy resulted in significantly improved student reception across all assessment categories. More students were encouraged to use LabSim and more students reported an improved educational outcome as assessed through the survey. The provision of dedicated LabSim workstations for those who were not able to run it on their personal computers also resulted in an improved student opinion of the technical aspects of LabSim. The most common suggestion in student feedback, however, is that they would benefit from an even larger LabSim presence in their course material. In particular, LabSim can be used as a demonstration tool in lectures and can be incorporated in mandatory simulation-based problems in their assignments.

Since the original pilot project in 2018, we have strived to be mindful of students' heavy workload while developing LabSim. The results from the two offerings of FEES we have explored so far suggest that there is an optimal level of incorporating simulations into teaching power electronics that would provide students with an incentive to invest time into them without devolving into a stressful and superfluous distraction. The improved survey results suggest that the LabSim project is currently moving in the right direction. More simulation-based material in FEES, to a reasonable extent, is indeed a promising course of action for the future. 


\section{Acknowledgement}

The authors would like to acknowledge Afshin Poraria and Rostant Kanick at the University of Toronto's Electrical Energy Systems Laboratory for their efforts to provide dedicated LabSim workstations to students of FEES.

\section{References}

[1] K. J. Branch and A. E. Butterfield, "Analysis of Student Interactions with Browser-Based Interactive Simulations," in 2015 ASEE Annual Conference \& Exposition, Seattle, WA, 2015.

[2] A. E. Butterfield, K. Branch and E. Trujillo, "First-Year Hands-On Design Course: Implementation and Reception," Chemical Engineering Education, vol. 49, no. 1, pp. 1926, 2015.

[3] C. Xie, C. Schimpf, J. Chao, S. Nourian and J. Massicotte, "Learning and teaching engineering design through modeling and simulation on a CAD platform," Computer Applications in Engineering Education, vol. 26, no. 7, pp. 824-840, 2018.

[4] G. Altuger-Genc, "Virtual Simulations to Support Applied Fluid Mechanics Course: A Pilot Implementation Overview," in 2015 ASEE Annual Conference \& Exhibition, Seattle, WA, 2015.

[5] S. Y. Chyung, J. Guarino, M. Scheeper, R. DeLeon, C. Adams and P. Williams, "The Value of Interactive Simulations Used in Undergraduate Math Class," in 2011 ASEE Annual Conference \& Exposition, Vancouver, BC, 2011.

[6] O. Akkoyun, "New simulation tool for teaching-learning processes in engineering education," Computer Applications in Engineering Education, vol. 25, no. 3, pp. 404-410, 2017.

[7] MathWorks, Inc., "Simulink - Simulation and Model-Based Design," 2018. [Online]. Available: https://www.mathworks.com/products/simulink.html. [Accessed 15 December 2018].

[8] Plexim GmbH, "PLECS Blockset," 2018. [Online]. Available: https://www.plexim.com/products/plecs_blockset. [Accessed 15 December 2018].

[9] J. Allmeling and W. Hammer, "PLECS - Piece-wise Linear Electrical Circuit Simulation for Simulink," in IEEE 1999 International Conference on Power Electronics and Drive Systems, Hong Kong, 1999.

[10] M. K. Elshazly and H. S. Timorabadi, "Board 68: Work in Progress: LabSim: An Ancillary Simulation Environment for Teaching Power Electronics Fundamentals," in 2019 ASEE Annual Conference \& Exposition, Tampa, FL, 2019.

[11] O. Rios and D. Fadda, "Using Computer Simulations in a Freshman Mechanical Engineering Course to Make Informed Design Decisions," in 2019 ASEE Annual Conference \& Exposition, Tampa, FL, 2019.

[12] A. Danesh-Yazdi, Y. Wu and O. Onipede Jr., "Interactive Simulation Modules (ISMs) in Vibrations," in 2019 ASEE Annual Conference \& Exposition, Tampa, FL, 2019. 
[13] A. Abramovitz, "Teaching Behavioral Modeling and Simulation Techniques for Power Electronics Courses," IEEE Transactions on Education, vol. 54, no. 4, pp. 523-530, 2011.

[14] Canvas, "How do I create Likert scale quiz questions?," 8 December 2018. [Online]. Available: https://community.canvaslms.com/docs/DOC-12942-415263277. [Accessed 16 December 2018].

[15] J. Gliem and R. Gliem, "Calculating, Interpreting, and Reporting Cronbach's Alpha Reliability Coefficient for Likert-Type Scales," in Midwest Research-to-Practice Conference in Adult, Continuing, and Community Education, Columbus, OH, 2003.

[16] J. Croasmun and L. Ostrom, "Using Likert-Type Scales in the Social Sciences," Journal of Adult Education, vol. 40, no. 1, pp. 19-22, 2011. 


\section{Appendix A-Sample LabSim Files for Simple Converter Circuit (Buck Converter)}
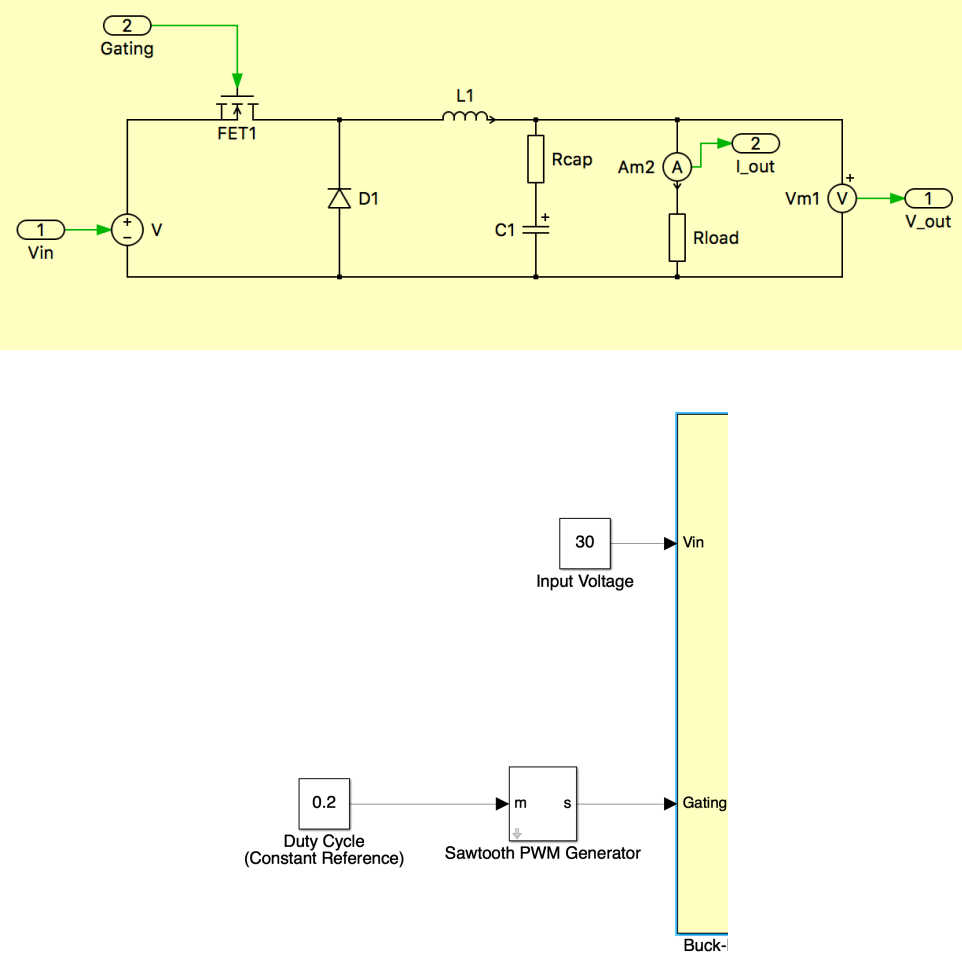

PLECS circuit for buck converter (top) and its Simulink circuit inputs (bottom).

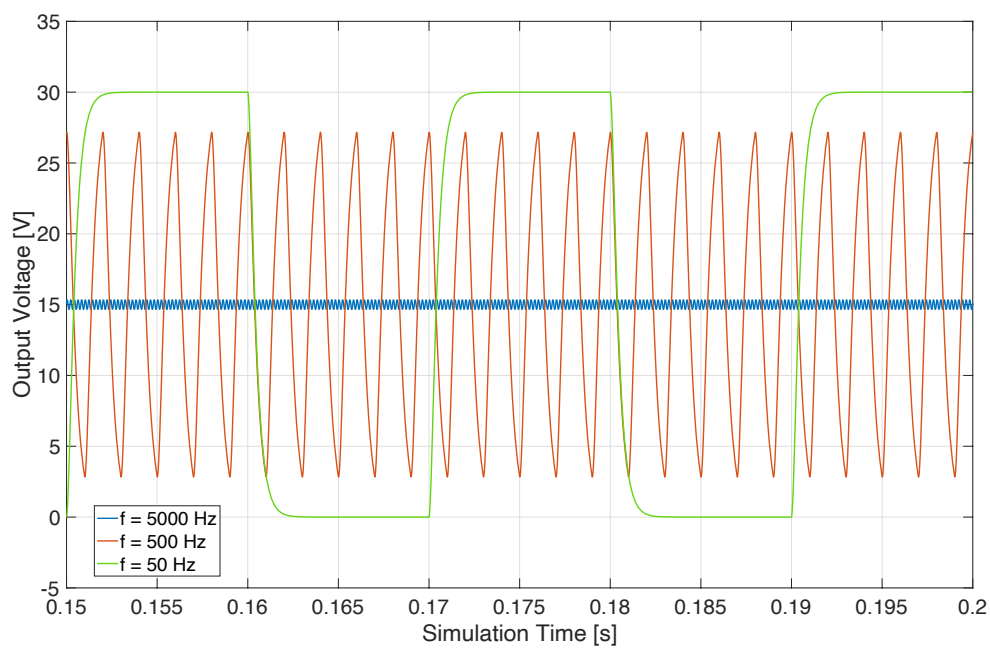

Example application for the LabSim buck converter model at an input voltage of $30 \mathrm{~V}$ and a duty cycle of $50 \%$ and constant filter values. The plot shows a comparison of the model's output voltage waveform at 3 different frequencies to investigate the influence of switching frequency on output voltage ripple. 


\section{Appendix B - Samples of LabSim-related Questions from Pre-lab Preparation Assignments}

\begin{tabular}{|c|c|c|}
\hline Laboratory Topic & Sample Questions & $\begin{array}{l}\text { Mandatory } \\
\text { or Optional }\end{array}$ \\
\hline Buck Converter & $\begin{array}{l}\text { 1. In the "Sawtooth PWM Generator block", you can } \\
\text { adjust the switching frequency by changing the value } \\
\text { in the "Carrier Frequency" field. The default value is } \\
10 \mathrm{kHz} \text {. Run the simulation at } 100 \mathrm{kHz}, 1 \mathrm{kHz} \text {, and } \\
100 \mathrm{~Hz} \text {. } \\
\text { a. Plot the output voltage and current } \\
\text { waveforms in each of the } 4 \text { cases. What is the } \\
\text { difference between the waveforms at } 1,10 \text {, } \\
\text { and } 100 \mathrm{kHz} \text { ? } \\
\text { b. Is there a major qualitative difference } \\
\text { between those } 3 \text { cases and the } 100 \mathrm{~Hz} \text { case? } \\
\text { If so, what is the reason behind this } \\
\text { difference? (Hint: try to use the PLECS } \\
\text { library to insert an ammeter into the inductor } \\
\text { branch of the converter, then plot the } \\
\text { inductor current in a Simulink scope for the } \\
\text { various frequencies). }\end{array}$ & Mandatory \\
\hline Buck Converter & $\begin{array}{l}\text { 1. Comment on the impact on the output voltage } \\
\text { waveform (in terms of ripple) if: } \\
\text { a. the inductor is changed from } 16.4 \mathrm{mH} \text { or } 17.3 \\
\mathrm{mH} \text { (depending on the style of inductor being } \\
\text { used in the lab) to } 64 \mathrm{mH} \\
\text { b. the switching frequency is changed from } 400 \mathrm{~Hz} \\
\text { to } 1000 \mathrm{~Hz} \\
\text { This question can be solved either theoretically or } \\
\text { using the LabSim buck converter file. }\end{array}$ & Optional \\
\hline DC/AC Converter & $\begin{array}{l}\text { 1. For an H-bridge quasi-square-wave VSI with } \\
\mathrm{V}_{\mathrm{dc}}=100 \mathrm{~V} \text {, a delay angle of } 80^{\circ} \text {, a switching } \\
\text { frequency of } 100 \mathrm{~Hz} \text {, and an RL load with } \mathrm{R}=10 \\
\text { Ohms, what is the influence of load inductance on } \\
\text { the output current's waveform? Comment on how } \\
\text { you expect the output current waveform to change } \\
\text { if the load inductance is increased by an order of } \\
\text { magnitude from } 5 \mathrm{mH} \text { to } 50 \mathrm{mH} \text {. How can you } \\
\text { explain this change? What other parameters of the } \\
\text { circuit can you adjust to induce a qualitatively } \\
\text { similar change on the output current waveform? } \\
\text { (This question can be answered either theoretically }\end{array}$ & Optional \\
\hline
\end{tabular}




\begin{tabular}{|c|c|c|c|}
\hline & & $\begin{array}{l}\text { or using the LabSim H-bridge VSI file. If } \\
\text { answering theoretically, please provide your } \\
\text { reasoning, analysis, and illustrative sketches. If } \\
\text { answering with LabSim, make sure you submit } \\
\text { appropriate supporting plots and explain how you } \\
\text { reached your conclusions based on these plots.) }\end{array}$ & \\
\hline $\begin{array}{l}\text { Grid Connected } \\
\text { Inverter }\end{array}$ & & $\begin{array}{l}\text { For } \mathrm{V}_{\mathrm{s}}=\mathrm{V}_{\mathrm{c}}=38 \mathrm{~V} \text { and } \mathrm{L}=17 \mathrm{mH} \text {, plot } \mathrm{P}=\operatorname{Re}(\overline{\mathrm{S}}) \\
\text { as a function of } \delta \text { for }-90^{\circ}<\delta<90^{\circ} \text {. For this (and } \\
\text { subsequent) problems, assume the system is } \\
\text { operating at } 60 \mathrm{~Hz} \text {. You can answer this question } \\
\text { analytically or using the LabSim grid-connected } \\
\text { inverter circuit with default values. } \\
\text { For } \mathrm{V}_{\mathrm{s}}=\mathrm{V}_{\mathrm{c}}=38 \mathrm{~V} \text { and } \mathrm{L}=17 \mathrm{mH} \text {, plot } \mathrm{Q}=\operatorname{Im}(\overline{\mathrm{S}}) \\
\text { as a function of } \delta \text { for }-90^{\circ}<\delta<90^{\circ} \text {. You can answer } \\
\text { this question analytically or using the LabSim grid- } \\
\text { connected inverter circuit with default values. }\end{array}$ & Optional \\
\hline
\end{tabular}


Appendix C- Detailed LabSim Survey Responses (Number of Students per Response)

\begin{tabular}{|c|c|c|c|c|c|}
\hline Educational Outcome & $\begin{array}{l}\text { Strongly } \\
\text { Disagree }\end{array}$ & Disagree & Neutral & Agree & $\begin{array}{c}\text { Strongly } \\
\text { Agree }\end{array}$ \\
\hline $\begin{array}{l}\text { LabSim models are relevant to the } \\
\text { lecture material. }\end{array}$ & 0 & 0 & 5 & 25 & 10 \\
\hline $\begin{array}{l}\text { LabSim models helped me } \\
\text { understand lecture material better. }\end{array}$ & 0 & 2 & 13 & 22 & 3 \\
\hline $\begin{array}{l}\text { LabSim models are relevant to the } \\
\text { lab experiments. }\end{array}$ & 1 & 1 & 5 & 17 & 16 \\
\hline $\begin{array}{l}\text { LabSim models helped me } \\
\text { understand lab experiments better. }\end{array}$ & 1 & 1 & 9 & 21 & 8 \\
\hline $\begin{array}{l}\text { LabSim helped me connect the } \\
\text { concepts and circuits I learned in } \\
\text { class to the lab experiments. }\end{array}$ & 1 & 0 & 11 & 23 & 5 \\
\hline $\begin{array}{l}\text { LabSim helped me solve, } \\
\text { understand and/or visualize } \\
\text { problem sets or past exams. }\end{array}$ & 1 & 13 & 13 & 11 & 2 \\
\hline $\begin{array}{l}\text { LabSim helped me solve, } \\
\text { understand, and/or visualize lab } \\
\text { preparation questions. }\end{array}$ & 1 & 1 & 4 & 22 & 12 \\
\hline Total & 5 & 18 & 60 & 141 & 56 \\
\hline
\end{tabular}

\begin{tabular}{|l|c|c|c|c|c|}
\hline \multicolumn{1}{|c|}{ Workload } & $\begin{array}{c}\text { Strongly } \\
\text { Disagree }\end{array}$ & Disagree & Neutral & Agree & $\begin{array}{c}\text { Strongly } \\
\text { Agree }\end{array}$ \\
\hline $\begin{array}{l}\text { I had time to use LabSim for } \\
\text { simulating the circuits and/or } \\
\text { experiments that are covered in } \\
\text { the course material. }\end{array}$ & 5 & 7 & 2 & 25 & 1 \\
\hline $\begin{array}{l}\text { The time and effort I invested into } \\
\text { learning how to use LabSim did } \\
\text { not significantly add to the } \\
\text { course's workload. }\end{array}$ & 0 & 3 & 13 & 15 & 9 \\
\hline $\begin{array}{l}\text { LabSim helped me reduce the } \\
\text { workload associated with } \\
\text { understanding lecture/tutorial } \\
\text { material. }\end{array}$ & 1 & 16 & 14 & 8 & 1 \\
\hline $\begin{array}{l}\text { LabSim helped me reduce the } \\
\text { workload associated with }\end{array}$ & 1 & 7 & 5 & 22 & 5 \\
\hline
\end{tabular}




\begin{tabular}{|c|c|c|c|c|c|}
\hline $\begin{array}{l}\text { understanding and/or preparing } \\
\text { for lab experiments. }\end{array}$ & & & & & \\
\hline $\begin{array}{l}\text { The time and effort I put into } \\
\text { learning and using LabSim is } \\
\text { justified by its impact in reducing } \\
\text { other course workload. }\end{array}$ & 0 & 6 & 20 & 13 & 1 \\
\hline $\begin{array}{l}\text { The time and effort I put into } \\
\text { learning and using LabSim is } \\
\text { justified by its impact on } \\
\text { improving my grades or } \\
\text { understanding of the course } \\
\text { material. }\end{array}$ & 0 & 4 & 19 & 15 & 2 \\
\hline $\begin{array}{l}\text { The time and effort I put into } \\
\text { learning and using LabSim is } \\
\text { justified by the experience I } \\
\text { gained in using industry-standard } \\
\text { simulation software } \\
\text { (Simulink/PLECS). }\end{array}$ & 0 & 2 & 10 & 22 & 6 \\
\hline Total & 7 & 45 & 83 & 120 & 25 \\
\hline
\end{tabular}

\begin{tabular}{|l|c|c|c|c|c|}
\hline \multicolumn{1}{|c|}{ Technical } & $\begin{array}{c}\text { Strongly } \\
\text { Disagree }\end{array}$ & Disagree & Neutral & Agree & $\begin{array}{c}\text { Strongly } \\
\text { Agree }\end{array}$ \\
\hline $\begin{array}{l}\text { The installation and activation } \\
\text { process for MATLAB and/or } \\
\text { PLECS is simple and } \\
\text { straightforward. }\end{array}$ & 3 & 8 & 4 & 16 & 9 \\
\hline $\begin{array}{l}\text { I was able to run LabSim on my } \\
\text { personal computer without } \\
\text { problems. }\end{array}$ & 3 & 4 & 0 & 22 & 11 \\
\hline $\begin{array}{l}\text { I was able to run LabSim on } \\
\text { university computers without } \\
\text { problems. }\end{array}$ & 1 & 2 & 18 & 11 & 8 \\
\hline $\begin{array}{l}\text { I found the Simulink/PLECS } \\
\text { software interface simple and } \\
\text { intuitive. }\end{array}$ & 1 & 2 & 6 & 26 & 5 \\
\hline $\begin{array}{l}\text { The PLECS interface (i.e. circuit } \\
\text { model) was easy to relate to the } \\
\text { circuit schematics and } \\
\text { components used in the lectures } \\
\text { and labs, respectively. }\end{array}$ & 0 & 2 & 6 & 25 & 7 \\
\hline
\end{tabular}




\begin{tabular}{|l|l|l|l|l|l|}
\hline $\begin{array}{l}\text { The Simulink implementation of } \\
\text { switching signals (i.e. circuit } \\
\text { inputs) was easy to understand. }\end{array}$ & 0 & 4 & 6 & 25 & 5 \\
\hline $\begin{array}{l}\text { The Simulink instrumentation (i.e. } \\
\text { oscilloscopes and harmonic } \\
\text { analyzers) helped me understand } \\
\text { the operation of the circuits. }\end{array}$ & 0 & 2 & 7 & 25 & 6 \\
\hline $\begin{array}{l}\text { I found it simple to modify the } \\
\text { provided models by changing } \\
\text { circuit components (e.g. remove } \\
\text { inductor, change capacitor value) } \\
\text { or operation parameters (e.g. } \\
\text { switching frequency). }\end{array}$ & 0 & 1 & 8 & 23 & 8 \\
\hline $\begin{array}{l}\text { I was able to simulate circuits } \\
\text { other than the ones provided by } \\
\text { the TA using the LabSim } \\
\text { interface. }\end{array}$ & 1 & 4 & 18 & 13 & 4 \\
\hline Total & $\mathbf{9}$ & $\mathbf{2 9}$ & $\mathbf{7 3}$ & $\mathbf{1 8 6}$ & $\mathbf{6 3}$ \\
\hline
\end{tabular}

